Article

\title{
Power Generation Expansion Optimization Model Considering Multi-Scenario Electricity Demand Constraints: A Case Study of Zhejiang Province, China
}

\author{
Peng Wang ${ }^{1(1)}$, Chunsheng Wang ${ }^{1, *}$, Yukun $\mathrm{Hu}^{2}$, Liz Varga ${ }^{2}$ and Wei Wang ${ }^{3}$ \\ 1 School of Information Science and Engineering, Central South University, Changsha 410083, China; \\ wp10751@csu.edu.cn \\ 2 School of Management, Cranfield University, Bedford MK43 0AL, UK; Yukun.Hu@cranfield.ac.uk (Y.H.); \\ liz.varga@cranfield.ac.uk (L.V.) \\ 3 College of Electrical Engineering, Guangxi University, Nanning 530004, China; specialwangwei@163.com \\ * Correspondence: wangcsu@csu.edu.cn; Tel.: +86-138-7599-6096
}

Received: 15 May 2018; Accepted: 5 June 2018; Published: 8 June 2018

check for updates

\begin{abstract}
Reasonable and effective power planning contributes a lot to energy efficiency improvement, as well as the formulation of future economic and energy policies for a region. Since only a few provinces in China have nuclear power plants so far, nuclear power plants were not considered in many provincial-level power planning models. As an extremely important source of power generation in the future, the role of nuclear power plants can never be overlooked. In this paper, a comprehensive and detailed optimization model of provincial-level power generation expansion considering biomass and nuclear power plants is established from the perspective of electricity demand uncertainty. This model has been successfully applied to the case study of Zhejiang Province. The findings suggest that the nuclear power plants will contribute $9.56 \%$ of the total installed capacity, and it will become the second stable electricity source. The lowest total discounted cost is 1033.28 billion RMB and the fuel cost accounts for a large part of the total cost (about 69\%). Different key performance indicators (KPI) differentiate electricity demand in scenarios that are used to test the model. Low electricity demand in the development mode of the comprehensive adjustment scenario (COML) produces the optimal power development path, as it provides the lowest discounted cost.
\end{abstract}

Keywords: power generation expansion; scenario analysis; provincial-level; linear programming

\section{Introduction}

Many countries in the world have experienced or are experiencing energy crisis and environmental pollution [1,2]. As the largest developing country in the world, China is also confronted with these serious issues. Due to the continuous population growth and the rapid economic development, the ever-increasing demand for energy in the whole society has reached an unprecedented height [3]. The energy crisis will seriously hinder the process of social and economic development, and environmental pollution will also affect the sustainable development of ecological civilization. We do not want to see any of these issues worsening in China, which is an increasingly influential country.

Electricity is an important secondary energy source. China's total electricity demand increased from $4193.5 \mathrm{TW}-\mathrm{h}$ in 2010 to $5802.0 \mathrm{TW}-\mathrm{h}$ in 2015 , with an average annual growth rate of $6.3 \%$. However, China's power generation structure is dominated by coal-fired plants, which contribute more than $40 \%$ of the country's carbon dioxide $\left(\mathrm{CO}_{2}\right)$ emissions [4]. Many researchers are exploring 
optimal power planning from different perspectives, that is, minimizing the total discounted cost or emissions from power generation systems. In general, most researchers use linear and non-linear, deterministic, and stochastic models to solve power generation expansion optimization problems. These models usually involve objective functions, decision variables, and necessary constraints. Some of them take the factors that are neglected by others into consideration to explore the impact of these factors on traditional power planning. Chen et al. [4] established a deterministic power planning model considering the non-carbon external costs in China, which mainly refer to the costs of biodiversity damage and health impact caused by power generation. Luz et al. [5] proposed a multi-objective power generation planning considering high penetration of renewable energy sources, especially the solar power. Chen et al. [6] took into account some low-carbon factors in power generation expansion planning, such as carbon prices or taxes, $\mathrm{CO}_{2}$ allowances, and the application of various low-carbon technologies. In order to solve parameter uncertainties in power generation capacity planning, Jin et al. [7] presented an inexact mixed-integer programming with interval-valued membership function. Cheng et al. [8] divided China's territory into 10 regions and discussed the multi-region optimization planning for the power industry, and conducted a comparative analysis with a single region model. Rentizelas et al. [9] incorporated life cycle external cost in the electricity generation mix, and found that most of the new installed capacity will be renewable in the near future. Zhang et al. [10] introduced environment cost, demand side response, and power supply reliability constraints into the generation expansion planning model, and adopted a discrete bacterial colony chemotaxis in order to solve this model. Feng et al. [11] applied stochastic programming to generate different scenarios in long-term power generation expansion planning. In addition, some commercial software, such as the long-range energy alternative planning (LEAP) system, is often used for power planning. Perwez et al. [12] proposed a LEAP model including three development scenarios, which was used to provide policy guidance for the Pakistan power industry. In [13], the LEAP model has also been applied to explore the optimal power development path in Panama. However, the original intention of developing commercial software is to investigate the entire energy-economy-environment (3E) system, rather than to investigate specific industries. Therefore, the performance of these commercial software is much lower than the generally mathematical model when solving the power planning problems [4].

Although many efforts have been given to all-round and in-depth study on power expansion planning problems from different levels and different perspectives, many studies have been conducted at the national level, rather than at the provincial level $[4,12,13]$. Besides, due to the lack of relevant parameters, biomass power plants are often overlooked [4], and nuclear power plants are seldom considered at the provincial-level because only six provinces in China have nuclear power plants so far. Furthermore, the aforementioned studies did not consider the impact of future uncertainty of electricity demand in power expansion planning.

In view of the above research gaps, a comprehensive and detailed optimization model of provincial-level power generation expansion considering biomass and nuclear power plants is established from the perspective of electricity demand uncertainty. This model has been successfully applied to the case study of Zhejiang Province (China) from 2016 to 2025. The rest of this paper is organized as follows: Section 2 describes the methodology and data; Section 3 presents the empirical analysis of Zhejiang's power planning; and, Section 4 suggests important conclusions.

\section{Methodology and Data}

Firstly, a comprehensive and detailed provincial-level power generation expansion (PGE) optimization model that combines both biomass and nuclear power plants was established to minimize the total discounted cost of the entire system, and it was applied to Zhejiang Province's (China) power planning for the horizon from 2016 to 2025 (PGE-Zhejiang model).

Secondly, the results of the PGE-Zhejiang model were analyzed to determine the optimal power development path. 
Thirdly, the LEAP-Zhejiang-Electricity model was developed to obtain diversified electricity demand values under various potential scenarios from the perspective of uncertainty in electricity demand.

The diversified electricity demand values obtained from the LEAP-Zhejiang-Electricity model were used as constraints for the PGE-Zhejiang model to explore the impact of future electricity demand uncertainty on the power expansion planning.

Finally, important conclusions were drawn for policy making in Zhejiang's power sector.

\subsection{PGE-Zhejiang Model}

In this model, eight types of power generation technologies are taken into account, as shown in Table 1, including coal-fired plants, natural gas plants, hydropower plants, pumped storage plants, wind power plants, solar photovoltaic power plants, biomass power plants, and nuclear plants. Besides, in order to make the power planning optimization scheme more reasonable and provide more referential value for policy-makers, it also considers some important general constraints, which are demand and supply balance constraints of electricity and power, safe operation constraints, capacity constraints, and variables non-negative constraints. The indices, parameters, and variables involved in this model are listed in Tables 1-3.

Table 1. List of indices.

\begin{tabular}{|c|c|c|}
\hline Indices & Description & Specifications \\
\hline$t$ & Power planning horizon & $2016-2025$ \\
\hline$i$ & Types of power generation plants, $i=1,2, \ldots, 8$ & $\begin{array}{l}\text { Coal, gas, hydro, pumped-storage, } \\
\text { wind, solar PV, biomass and nuclear }\end{array}$ \\
\hline$j$ & Types of pollutant emission, $j=1,2,3,4$ & $\mathrm{NO}_{\mathrm{x}}, \mathrm{CO}_{2}, \mathrm{CO}, \mathrm{SO}_{2}$ \\
\hline
\end{tabular}

Table 2. List of parameters.

\begin{tabular}{|c|c|c|}
\hline Parameters & Description & Unit \\
\hline$T C_{i, 2015}$ & The initial installed capacity of power plants $i$ in year 2015 & MW \\
\hline$I C_{i, 2015}$ & Investment cost of power plants $i$ in year 2015 & $\mathrm{RMB} / \mathrm{kW}$ \\
\hline$O M_{i, 2015}$ & O\&M cost of power plants $i$ in year 2015 & $\mathrm{RMB} / \mathrm{kWh}$ \\
\hline$F C_{i, 2015}$ & Fuel cost of power plants $i$ in year 2015 & $\mathrm{RMB} / \mathrm{kWh}$ \\
\hline $\operatorname{Gov}_{i, 2020}$ & Planned installation capacity in year 2020 & MW \\
\hline$P D_{t}$ & Electricity demand in year $t$ & $10^{8} \mathrm{kWh}$ \\
\hline$P L_{t}$ & Peak load demand in year $t$ & $10^{4} \mathrm{MW}$ \\
\hline$E C_{t}$ & External purchased electricity price in year $t$ & $\mathrm{RMB} / \mathrm{kWh}$ \\
\hline $\operatorname{Len}_{i}$ & Life cycle of power plants $i$ & year \\
\hline$r$ & Discount rate & $\%$ \\
\hline$\alpha_{i}$ & Change rate of investment cost of power plants $i$ & $\%$ \\
\hline$\beta_{i}$ & Change rate of O\&M cost of power plants $i$ & $\%$ \\
\hline$\gamma_{i}$ & Change rate of fuel cost of power plants $i$ & $\%$ \\
\hline$q_{i}$ & Annual growth rate of installed capacity of power plants $i$ & $\%$ \\
\hline$\lambda_{i}$ & Environmental cost coefficient of nuclear plants & - \\
\hline$\rho$ & Load margin coefficient & - \\
\hline$\eta$ & The proportional coefficient of purchased electricity and total electricity demand & - \\
\hline$\psi$ & The proportional coefficient of purchased power and total peak load demand & - \\
\hline$\omega$ & Safety operation coefficient of power system & - \\
\hline$c f_{i}$ & Capacity factor of power plants $i$ & - \\
\hline$e f_{j, t}$ & Pollutant emission coefficient of type $\mathrm{j}$ for power plants $i$ & $\mathrm{~g} / \mathrm{kWh}$ \\
\hline$e v_{j}$ & Environmental value of pollutant emission type $j$ & $\mathrm{RMB} / \mathrm{Kg}$ \\
\hline $\operatorname{pen}_{j}$ & Penalty of pollutant emission type $j$ & $\mathrm{RMB} / \mathrm{Kg}$ \\
\hline
\end{tabular}

Table 3. List of variables.

\begin{tabular}{ccc}
\hline Variables & Description & Unit \\
\hline$P G_{i, t}$ & Annual electricity generated from plants $i$ in year $t$ & MWh \\
$B E_{t}$ & The amount of electricity purchased in year $t$ & $\mathrm{MWh}$ \\
$B P_{t}$ & The amount of power purchased in year $t$ & $\mathrm{MW}$ \\
\hline
\end{tabular}




\subsubsection{Objective Function}

The objective function of this model Equation (1) is to achieve a balance of supply and demand of electricity and power, and to minimize the economic cost of the entire system during the planning horizon, including investment cost, operation and maintenance (O\&M) cost, fuel cost, environmental cost, and electricity procurement cost. The specific calculation process is as follows Equations (1)-(6):

$$
\min F=\left(F_{i n v}+F_{o m}+F_{f u}+F_{e n v}+F_{b u y}\right)
$$

(1) Total investment cost. To take into account the continuous innovation of power generation technology, a parameter $\alpha$ is introduced in Equation (2), that is, the rate of change in investment costs [14].

$$
F_{i n v}=\sum_{t=2016}^{2025} \sum_{i=1}^{8} I C_{i, 2015} \times T C_{i, t} \times\left(1+\alpha_{i}\right)^{(t-2015)} \times \frac{r /(1+r)}{\left(1-(1+r)^{-L e n_{i}}\right)} \times(1+r)^{-(t-2015)}
$$

(2) Total operation and maintenance cost. To take into account the complexity and diversity of components in O\&M costs, a parameter $\beta$ is introduced in Equation (3), that is, the rate of change in O\&M costs [14].

$$
F_{o m}=\sum_{t=2016}^{2025} \sum_{i=1}^{8} O M_{i, 2015} \times\left(1+\beta_{i}\right)^{(t-2015)} \times P G_{i, t} \times(1+r)^{-(t-2015)}
$$

(3) Total fuel cost. To take into account the finiteness of resources, a parameter $\gamma$ is also introduced in Equation (4), that is, the rate of change in fuel costs.

$$
F_{f u}=\sum_{t=2016}^{2025} \sum_{i} F C_{i, 2015} \times\left(1+\gamma_{i}\right)^{(t-2015)} \times P G_{i, t} \times(1+r)^{-(t-2015)}, i \in(1,2,7,8)
$$

(4) Total environment cost. The total environment cost includes two components, the former part is the environmental costs for conventional plants (coal-fired plants and natural gas plants) and biomass power plants, and the latter part is the environmental costs for nuclear plants [10].

$$
F_{e n v}=\sum_{t=2016}^{2025}\left[\sum_{i=1,2,7} \sum_{j=1}^{4} e f_{j, i} \times\left(e v_{j}+p e n_{j}\right) \times P G_{i, t}+\sum_{i=8} \lambda_{i} \times P G_{i, t}\right] \times(1+r)^{-(t-2015)}, i \in(1,2,7,8)
$$

(5) Total external electricity procurement cost.

$$
F_{b u y}=\sum_{t=2016}^{2025} B E_{t} \times E C_{t} \times(1+r)^{-(t-2015)}
$$

\subsubsection{Physical Constraints}

(1) Demand and supply balance of electricity and power. In this paper, the unit for electricity is TW-h, and GW for power. Given that the electricity supply planning scheme has to meet the province's increasing electricity demand, this study presents four specific sub-constraints, as shown in Equations (7)-(10). The parameter $\eta$ in Equation (9) is the proportional coefficient of purchased electricity and total electricity demand, which is estimated from the electricity data 
in [15]. The parameter $\psi$ in Equation (10) is the proportional coefficient of purchased power and total peak load demand, also estimated from the power data in [15].

$$
\begin{gathered}
\sum_{i=1}^{8} P G_{i, t}+B E_{t} \geq P D_{t} \\
P G_{i, t} \leq 6000 \times T C_{i, t} \times c f_{i} \\
\eta \times P D_{t} \geq B E_{t} \\
\psi \times P L_{t} \leq B P_{t}
\end{gathered}
$$

(2) Power system security operation. Taking into account the intermittent nature of renewable energy power generation technology, the parameter $\omega$, represents the safe operation coefficient of the power system, which is used in Equation (11) [4]. The parameter $\rho$ in Equation (12) is the load margin coefficient, which is used to meet the peak load demand.

$$
\begin{gathered}
\omega \times \sum_{i=1}^{8} P G_{i, t} \geq \sum_{i=5}^{6} P G_{i, t} \\
\sum_{i=1}^{8} T C_{i, t}+B P_{t} \geq(1+\rho) \times P L_{t}
\end{gathered}
$$

(3) Installed capacity within the planning horizon. The cumulative installed capacity in 2020 should be lower than the capacity in the planning document [15].

$$
T C_{i, 2020} \leq \operatorname{Gov}_{i, 2020}
$$

(4) Non-negative decision variables.

$$
P G_{i, t} \geq 0, B E_{t} \geq 0, B P_{t} \geq 0
$$

\subsubsection{Data Sources}

Using data from the '13th Five-Year Power Development Plan' of Zhejiang Province (2016-2020) [15], combined with actual data in recent years (2016-2017), this study mainly focuses on the '14th Five-Year Power Development Plan' in Zhejiang Province and it provides suggestions for relevant policy-makers. A discount rate of $7 \%$ per annum is adopted for all power plants, which is derived from the value that is used in [16].

Important economic parameters that are involved in the PGE-Zhejiang model come from [16,17], including the power plant's life cycle, investment cost (USD/kW), O\&M cost (RMB/kWh), and fuel cost (USD/MWh). These parameters were converted into RMB $/ \mathrm{kW}, \mathrm{RMB} / \mathrm{kWh}$, and $\mathrm{RMB} / \mathrm{MWh}$ by using the average exchange rate of 6.15, as reported by the Organisation for Economic Co-operation and Development (OECD) in 2013. The rate of change in investment cost comes from [4,17]; the rate of change in O\&M cost comes from [12]; the rate of change in fuel costs comes from [17,18]; and, the capacity factor of different power plants comes from $[4,9,12]$.

Those power related parameters, such as electricity demand and peak load data from 2021 to 2025 , are predicted by the grey prediction method that is used in [19]. The price of electricity purchased from the outside is estimated from [20,21]. In addition, an empirical value " 6000 " of annual working hours is adopted for all power plants. Table 4 shows the key economic and technical data for different generations of technology throughout the planning horizon. 
Those economic and technical parameters that are related to pollutant emissions, including $e f_{j, t}$, $e v_{j}$, and $p e n_{j}$, are from the National Bureau of Statistics of China and the major pollutants reduction planning of Zhejiang Province [10,22].

Table 4. Key economic and technical data for different generations of technology.

\begin{tabular}{cccccccccc}
\hline Parameter & Unit & Coal & Gas & Hydro & Pumped-Storage & Wind & Solar & Biomass & Nuclear \\
\hline$T C_{i, 2015}$ & $\mathrm{MW}$ & 46,060 & 12,280 & 6940 & 3080 & 1040 & 2200 & 1030 & 6570 \\
$I C_{i, 2015}$ & $\mathrm{RMB} / \mathrm{kW}$ & 5737.95 & 4126.65 & 3677.70 & 3677.70 & 7632.15 & 4637.10 & 5256.22 & $1,4206.50$ \\
$\mathrm{OM} \mathrm{M}_{i, 2015}$ & $\mathrm{RMB} / \mathrm{kWh}$ & 0.0250 & 0.0200 & 0.0650 & 0.0650 & 0.0600 & 0.1000 & 0.0185 & 0.0400 \\
$F C_{i, 2015}$ & $\mathrm{RMB} / \mathrm{kWh}$ & 0.3969 & 0.5073 & 0.0000 & 0.0000 & 0.0000 & 0.0000 & 0.2500 & 0.0574 \\
$\mathrm{Gov}_{i, 2020}$ & $\mathrm{MW}$ & 4,6350 & 1,2530 & 7050 & 4940 & 4000 & 8020 & 1100 & 9100 \\
$\mathrm{Len}_{i}$ & $\mathrm{year}$ & 40 & 30 & 80 & 80 & 25 & 25 & 40 & 60 \\
$c f_{i}$ & - & 0.6056 & 0.3637 & 0.4188 & 0.4000 & 0.2700 & 0.1700 & 0.5600 & 0.8600 \\
$\alpha_{i}$ & $\%$ & -1.50 & -1.00 & 1.50 & 1.50 & -4.00 & -5.00 & -2.00 & 0.00 \\
$\beta_{i}$ & $\%$ & 7.27 & 3.22 & 0.76 & 0.76 & 0.45 & -3.31 & -0.27 & 5.02 \\
$\gamma_{i}$ & $\%$ & 1.90 & 2.90 & 0.00 & 0.00 & 0.00 & 0.00 & 1.70 & 3.40 \\
$q_{i}$ & $\%$ & 0.10 & 0.40 & 0.30 & 9.90 & 30.90 & 29.50 & 1.30 & 6.70 \\
\hline
\end{tabular}

\subsection{LEAP-Zhejiang-Electricity Model}

\subsubsection{Model Description}

Our previous research on the Logarithmic Mean Divisia Index (LMDI) decomposition method [19] found that the factors affecting the growth of energy demand in a region are mainly the scale effect, structure effect, and the efficiency effect. Electricity is an important energy source, and the same method can be applied to investigate the factors affecting its consumption. Based on this idea, the growth of electricity consumption in the three industries is decomposed into the scale effect, structure effect, and efficiency effect. The decomposition results are listed in Table 5, in which the key performance indicators (KPI) for the aforementioned three effects are gross domestic product (GDP) growth rate, proportion of industrial structure, and power consumption intensity, respectively.

Table 5. Decomposition results of electricity consumption (TW-h).

\begin{tabular}{ccccc}
\hline Years & Total Effect & Scale Effect & Structure Effect & Efficiency Effect \\
\hline 2011 & 26.23 & 40.36 & -1.33 & -12.80 \\
2012 & 5.44 & 19.56 & -5.15 & -8.97 \\
2013 & 19.44 & 24.90 & -9.35 & 3.89 \\
2014 & 7.22 & 18.91 & -0.24 & -11.45 \\
2015 & 2.48 & 20.24 & -8.39 & -9.37 \\
$2011-2015$ & 34.57 & 82.94 & -22.96 & -25.41 \\
\hline
\end{tabular}

In view of the above decomposition results, the demand module of the Long-range Energy Alternatives Planning (LEAP) system was used to develop some related and meaningful electricity demand scenarios [23]. These scenarios can be divided into five categories according to the different values of the parameters, including baseline (BAS) scenario, scale effect (SCA) scenario, structure effect (STR) scenario, efficiency effect (EFF) scenario, and comprehensive adjustment (COM) scenario. BAS scenario is established to provide benchmarks for other scenarios, and the key assumptions in BAS scenario are based on the data mentioned in the Zhejiang economic and social development planning document, including population growth rate, gross domestic product (GDP), and three industries structure. The difference between the various scenarios is their KPI value, while other parameters are consistent with the BAS scenario. SCA scenario has two sub-scenarios (SCAL and SCAH) with low and high "GDP growth rate", respectively. STR scenario has two sub-scenarios (STRL and STRH) with low and high pace adjustment of three industries structure, respectively. The EFF scenario describes the change of electricity consumption intensity in various industries. 
COM scenario also has two sub-scenarios (COML and COMH) with low and high electricity demand, respectively. Low electricity demand (COML) scenario consists of low GDP growth rate (SCAL), high speed industry structure change (STRH) and electricity intensity values under efficiency effect adjustment scenario. High electricity demand (COMH) scenario consists of high GDP growth rate (SCAH), low speed industry structure change (STRL), and electricity intensity values under benchmark scenario, and other key parameters are consistent with the benchmark scenario. The findings of various electricity demand scenarios are used as the demand constraints to modify and improve the results of the PGE-Zhejiang model.

\subsubsection{Data Sources}

In this model, the population growth rate is assumed to be $0.5 \%$, and the urbanization rates in 2020 and 2025 are 0.7 and 0.75 , respectively, which can be obtained from [24]. For the BAS scenario and other scenarios than the SCA scenario, the KPI "GDP growth rate" is set to be 7\%, according to the data in [25]. The GDP growth rates for SCAL and SCAH are $6.6 \%$ and $7.5 \%$, respectively. Table 6 lists the forecasted proportion of industrial structure under different structure effects in 2020 and 2025. Further, according to the development trend in 2011-2015, the annual rate of change in the intensity of electricity consumption in various industries under the BAS scenario is obtained, and the results under the EFF scenario are listed in Table 7.

Table 6. Three industries structure under different structure effects.

\begin{tabular}{cccc}
\hline Years & $\mathbf{2 0 1 6}$ & $\mathbf{2 0 2 0}$ & $\mathbf{2 0 2 5}$ \\
\hline STRL & $4.16: 44.86: 50.99$ & $3.65: 41.56: 54.79$ & $3.15: 36.48: 60.37$ \\
STRH & $4.16: 44.86: 50.99$ & $3.65: 39.78: 56.57$ & $3.15: 34.68: 62.17$ \\
\hline
\end{tabular}

Table 7. Annual rate of change in the intensity of electricity consumption under efficiency effects.

\begin{tabular}{cccccc}
\hline Primary Industry & Industry & Construction & Tertiary Industry & Urban Residents & Rural Residents \\
\hline $1.04 \%$ & $-1.80 \%$ & $-2.40 \%$ & $-1.60 \%$ & $3.3 \%$ & $6.5 \%$ \\
\hline
\end{tabular}

\section{Results and Discussion}

In this section, results and relevant discussions are presented, including the optimal power generation expansion path, cost-benefit analysis of PGE-Zhejiang model, results analysis of LEAP-Zhejiang-Electricity model, and power generation expansion under multi-scenario electricity demand constraints.

\subsection{Results Analysis of Power Generation Expansion during the Planning Horizon}

The installed capacity of different types of power generation technologies and their proportions throughout the planning horizon are shown in Figures 1 and 2. The total installed capacity of the above-mentioned power generation technologies may reach $132.65 \mathrm{GW}$ in 2025 , with an annual growth rate of approximately $6.37 \%$. In terms of the growth rate in Figure 1, renewable energy technologies (wind and solar PV plants) are the fastest, however, when it comes to total installed capacity in Figure 2, coal-fired plants and natural gas plants still dominate. Since the total installed nuclear power capacity in Zhejiang Province ranks third in China, it is reasonable that nuclear power accounts for $9.56 \%$ of the total installed capacity during the planning horizon in this paper. 


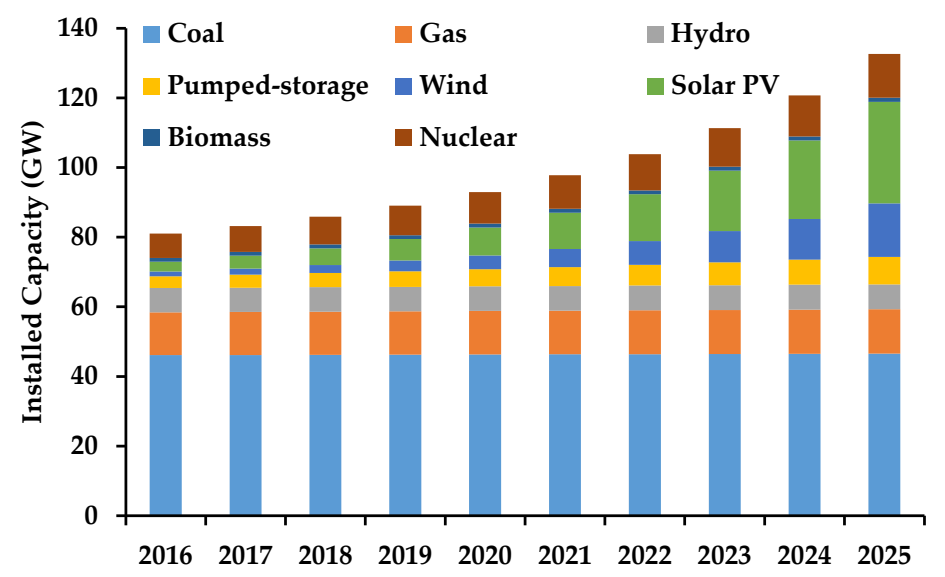

Figure 1. Installed capacities mix in the planning horizon.

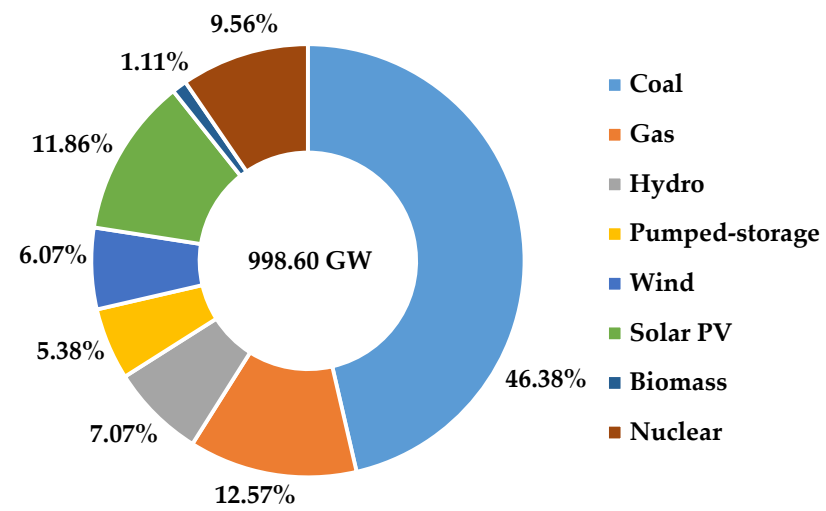

Figure 2. Proportions of installed capacities in the planning horizon.

The optimal power development planning for Zhejiang Province from 2016 to 2025 can be obtained from the PGE-Zhejiang model, including optimal power generation mix, external purchased electricity, and external purchased power. As shown in Figure 3, as the demand for electricity continues to increase, power generation increases year by year, from 243.80 TW-h in 2016 to 327.59 TW-h in 2025 . Meanwhile, coal-fired plants will continue to provide stable electricity output, ensuring the basic electricity demand in Zhejiang Province. Although the total installed capacity of the nuclear power plants accounts for only $9.56 \%$ of the total installed capacity during the planning horizon, its power generation capacity is only ranked after the coal-fired plants and has become another major source of maintaining the balance of supply and demand in Zhejiang's power system. In addition, renewable energy technologies will also make a significant contribution to the electricity demand in Zhejiang, which may provide the maximum 'about $6.18 \%$ ' of power generation during the planning horizon. In fact, biomass power plants are often overlooked in some power planning studies, but this does not indicate that they are not important. Although they provide only $37.18 \mathrm{TW}-\mathrm{h}(1.31 \%$ of the total) during the planning horizon, their role in reducing environmental pollution due to large amounts of straw burning is indispensable. However, they usually cannot provide sufficient amount of electricity and can only meet $70 \%$ of the electricity demand. In this case, extra electricity is in need to meet the peak demand, which will be purchased from the outside. As shown in Figure 4, both the external purchased electricity and power will continue to increase during the planning horizon. The former will vary from 125.60 TW-h in 2016 to 168.76 TW-h in 2025, and the latter will change from $26.50 \mathrm{GW}$ in 2016 to $40.71 \mathrm{GW}$ in 2025. 


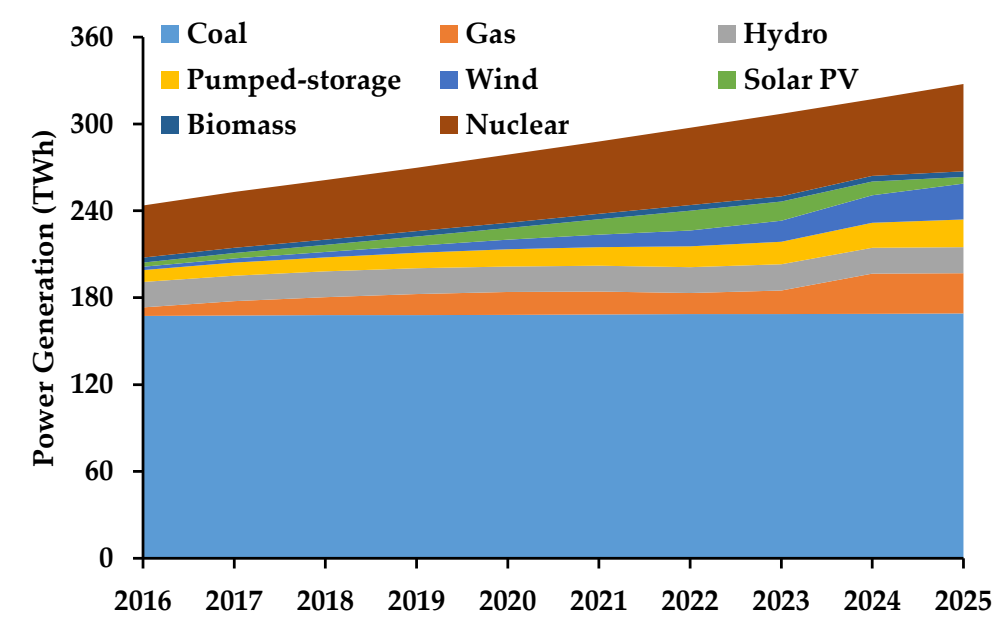

Figure 3. Power generation of different plants in the planning horizon.

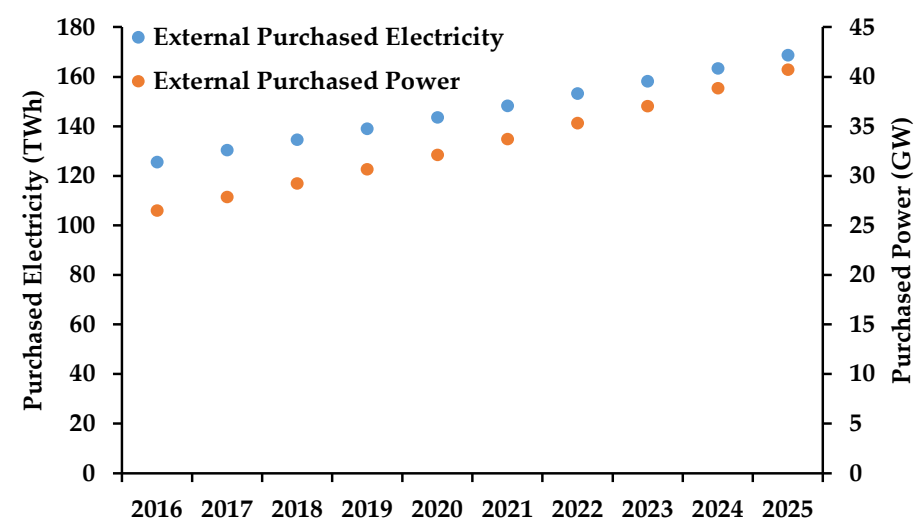

Figure 4. External purchased electricity and power in the planning horizon.

\subsection{Cost-Benefit Analysis of PGE-Zhejiang Model during the Planning Horizon}

Since the objective function of the PGE-Zhejiang model is to minimize the total discounted cost of the whole power system, it is necessary to examine changes in various costs during the planning horizon. As shown in Figure 5, the lowest total discounted cost is 1033.28 billion RMB, in which the fuel cost accounts for a large part of the total cost (about 69\%). This means that, in order to reduce the cost of the system in the future, the proportion of investment in fossil fuel power plants should be appropriately reduced because their fuel costs are about 8 to 10 times higher than that of the nuclear plants. In contrast, from the perspective of economic costs and environmental protection, the proportions of investment in renewable energy power plants and nuclear power plants should increase. In the near future, they can become a good substitute for fossil fuel power plants to some extent. In addition to fuel cost, the cumulative share of outsourcing electricity cost is also large, which is about $16.36 \%$. As shown in Figure 6, the outsourcing electricity cost changes from 19.64 billion RMB in 2016 to 14.35 billion RMB in 2025 with a downward trend, as a result of the vigorous promotion and technological innovation of renewable energy power generation technologies. During the whole planning horizon, the environmental cost for the system to be paid for environmental pollution is about 50.01 billion RMB, accounting for $4.84 \%$ of the total cost. Similarly, some effective measures, including improving the proportion of renewable energy power plants as well as retrofit the fossil fuel power plants with advanced carbon capture and storage technology can be applied, through which this part of expenditure will be largely reduced. 


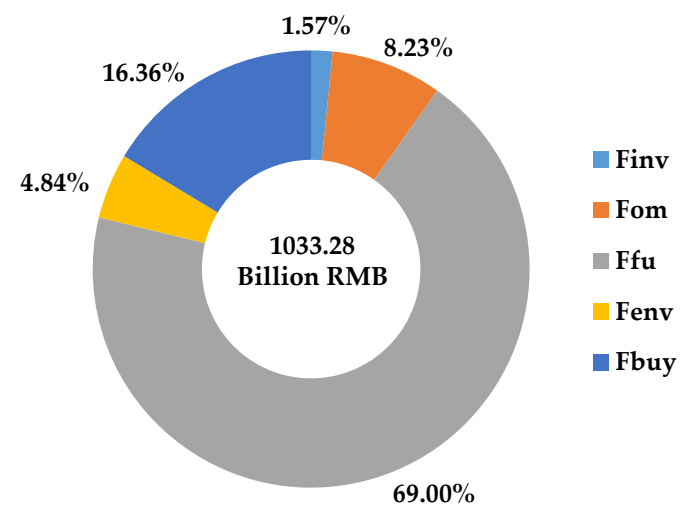

Figure 5. Proportions of various costs in the planning horizon.

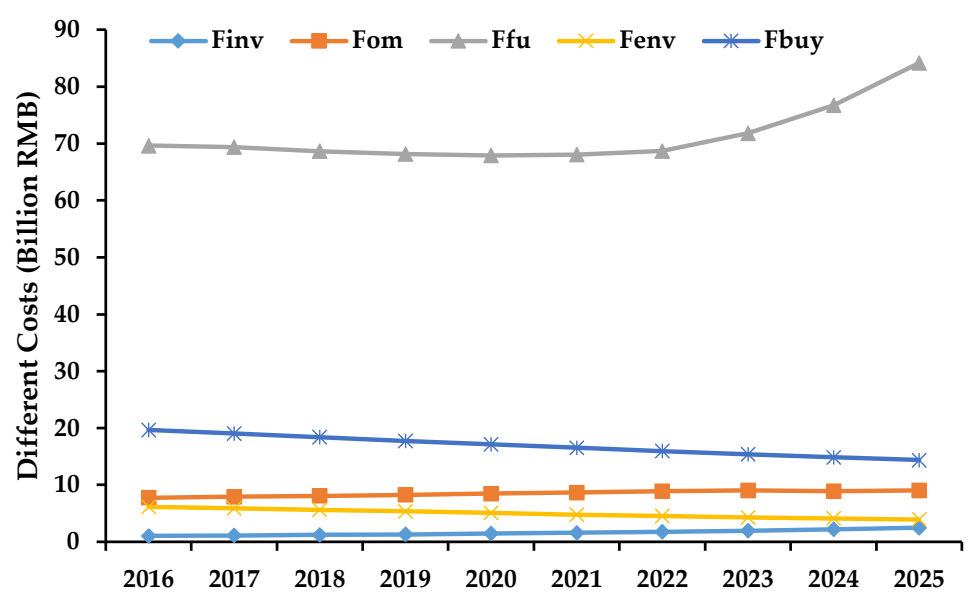

Figure 6. Changes in various costs in the planning horizon.

\subsection{Results Analysis of LEAP-Zhejiang-Electricity Model}

Table 8 lists the electricity demands under various possible scenarios that are calculated using the LEAP-Zhejiang-Electricity model. The values obtained from the PGE-Zhejiang model are regarded as the original (ORI) scenario. The total electricity demand under the BAS scenario changes from 378.53 TW-h in 2016 to 607.35 TW-h in 2025, with an annual growth rate of $6 \%$. In the wake of rapid development in the regional economy, the demand for electricity will continue to increase. As a result, electricity demand values under the SCAH scenario are obviously higher than that under the SCAL scenario, because the former has a higher KPI- "GDP growth rate". The adjustment of the macro industrial structure is bound to have a profound effect on the changes in electricity demand in the region. Therefore, electricity demand values under the STRH scenario with high-speed transforming from the secondary industry to the tertiary industry are significantly lower than that under the STRL scenario, which is because most industries in the secondary industry have higher energy intensity. With the improvement of energy efficiency, the electricity demand under the EFF scenario has been reduced to some extent when compared to the BAS scenario. When considering all KPIs in a comprehensive manner, electricity demand values under the COMH and COML scenarios are lower than that under the BAS scenario, and they are only $92 \%$ and $78 \%$ of the BAS scenario value, respectively. This result shows that electricity demand is closely related to the aforementioned factors. In the process of power planning, only comprehensive consideration of various factors will enable policy-makers to obtain the most reliable results. It is also worth noting that, during the planning horizon, the SCAH scenario always has the highest electricity demand values, which indicates that the GDP growth rate will become the primary KPI affecting the electricity demand. 
Table 8. The values of electricity demand in various possible scenarios (TW-h).

\begin{tabular}{ccccccccccc}
\hline Scenario & $\mathbf{2 0 1 6}$ & $\mathbf{2 0 1 7}$ & $\mathbf{2 0 1 8}$ & $\mathbf{2 0 1 9}$ & $\mathbf{2 0 2 0}$ & $\mathbf{2 0 2 1}$ & $\mathbf{2 0 2 2}$ & $\mathbf{2 0 2 3}$ & $\mathbf{2 0 2 4}$ & $\mathbf{2 0 2 5}$ \\
\hline ORI & 369.40 & 383.35 & 395.93 & 408.93 & 422.35 & 436.21 & 450.52 & 465.31 & 480.58 & 496.35 \\
BAS & 378.53 & 399.06 & 420.68 & 443.45 & 467.44 & 492.63 & 519.15 & 547.06 & 576.43 & 607.35 \\
SCAH & 378.53 & 400.69 & 424.13 & 448.93 & 475.16 & 502.83 & 532.09 & 563.02 & 595.71 & 630.27 \\
SCAL & 378.53 & 397.75 & 417.93 & 439.11 & 461.34 & 484.61 & 509.01 & 534.61 & 561.46 & 589.62 \\
STRH & 352.88 & 359.12 & 374.48 & 399.52 & 434.82 & 451.35 & 468.38 & 485.91 & 503.93 & 522.44 \\
STRL & 354.75 & 363.05 & 380.70 & 408.24 & 446.31 & 463.49 & 481.19 & 499.43 & 518.20 & 537.51 \\
EFF & 377.28 & 396.43 & 416.53 & 437.64 & 459.79 & 482.98 & 507.31 & 532.83 & 559.60 & 587.68 \\
COMH & 354.75 & 363.67 & 382.66 & 412.40 & 453.63 & 473.00 & 493.06 & 513.81 & 535.26 & 557.44 \\
COML & 351.71 & 356.26 & 369.25 & 391.07 & 422.12 & 435.30 & 448.77 & 462.51 & 476.52 & 490.79 \\
\hline
\end{tabular}

\subsection{Results Analysis of Power Generation Expansion under Multi-Scenario Electricity Demand Constraints}

The above multi-scenario electricity demand values were further substituted into the PGE-Zhejiang model as different constraints. By exploring the results of the PGE-Zhejiang model under each electricity demand scenario, this model has been refined, as shown below.

\subsubsection{Results Analysis of Parameters Optimization}

Based on the fact that there is a large gap between the electricity demand values under different scenarios, the parameters of the PGE-Zhejiang model need to be corrected when considering the multiple scenarios of electricity demand constraints. Table 9 lists the corrected parameters. As shown in this table, the proportion of external purchased electricity is in the range of 0.33 to 0.45 , which is consistent with electricity demand under different scenarios during the planning horizon. Meanwhile, the average working hours of the plants should also be adjusted to change their outputs.

Table 9. Results of parameter optimization.

\begin{tabular}{ccc}
\hline Scenario & Average Working Hours of Power Plants & $\boldsymbol{\eta}$ \\
\hline ORI & 6000 & 0.34 \\
BAS & 6300 & 0.43 \\
SCAH & 6300 & 0.45 \\
SCAL & 6300 & 0.42 \\
STRH & 6100 & 0.36 \\
STRL & 6100 & 0.38 \\
EFF & 6200 & 0.42 \\
COMH & 6100 & 0.40 \\
COML & 6000 & 0.33 \\
\hline
\end{tabular}

3.4.2. Analysis of Total Discounted Costs under Different Electricity Demand Scenarios

Figure 7 shows the proportions of various costs under different scenarios during the planning horizon. There are no significant differences in investment costs and operating costs under the nine scenarios. In contrast, with the changes in electricity demand under different scenarios, the output of power plants, fuel consumption, and the proportion of electricity that needs to be purchased from external grids have undergone major changes, resulting in large fluctuations in fuel cost, environment cost, and electricity procurement cost. It is worth noting that the SCAH scenario has the highest proportion of external electricity procurement cost, while the O\&M cost, fuel cost, and environment cost are the lowest. This means that, in the SCAH scenario, the growing demand for electricity can be met by increasing the proportion of purchased electricity. However, this mode is not advisable for long distance transmission, which is unreliable to ensure the safety of the power system. 


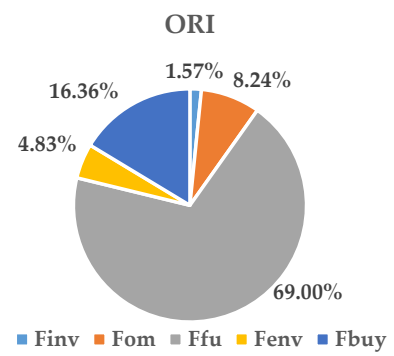

SCAL

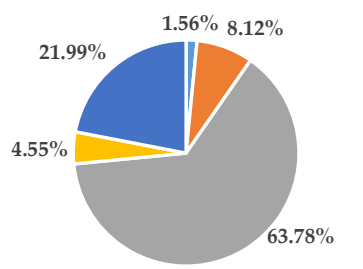

- Finv - Fom - Ffu - Fenv - Fbuy

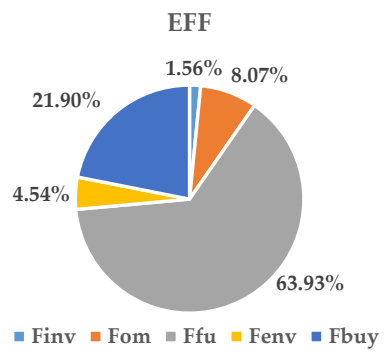

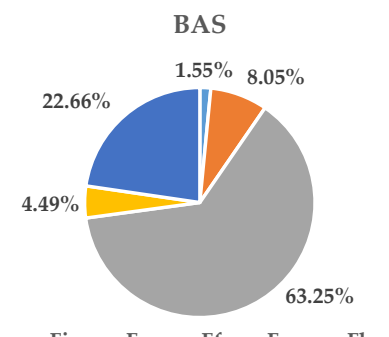

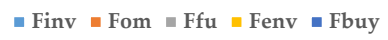
STRH

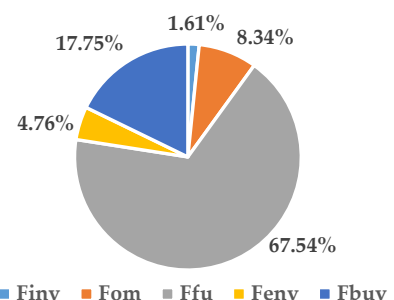

$\mathrm{COMH}$

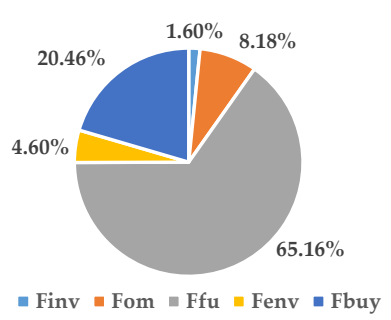

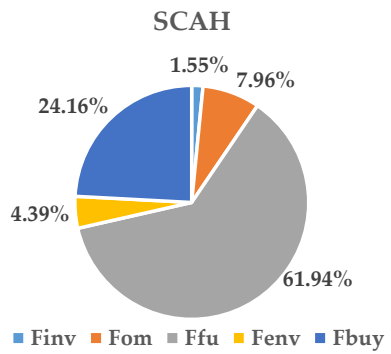

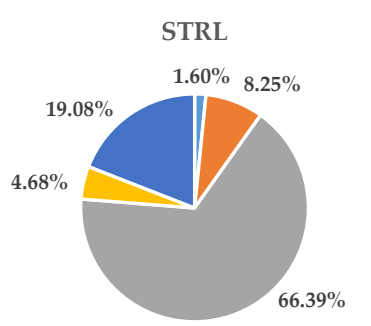

$\square$ Finv $₫$ Fom $₫$ Ffu $₫$ Fenv $\square$ Fbuy

COML

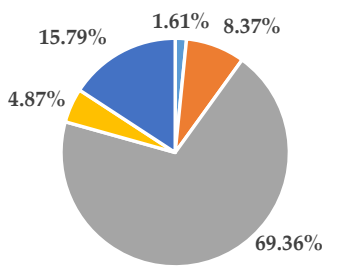

$\square$ Finv $\backsim$ Fom $\backsim$ Ffu $\backsim$ Fenv $\backsim$ Fbuy

Figure 7. Proportions of various costs under different scenarios.

As can be seen from Figure 8, the total discounted costs under various scenarios are quite different. The value in ORI scenario refers to the actual value obtained from the PGE-Zhejiang model, which is 1033.28 billion RMB. In the eight scenarios that were developed in the LEAP-Zhejiang-Electricity model, BAS has the highest total discounted cost, which is 1050.53 billion RMB. There are only four scenarios (STRH, STRL, COMH, and COML) under which the total discounted costs are lower than the value in ORI, which means that the development mode of these four scenarios can be applied to power expansion planning. In other words, accelerating the transformation and upgrading of the industrial structure should be a key consideration in power expansion planning. Besides, the development mode of comprehensive adjustment scenarios is also a good option, which takes into account all three effects (SCA, STR, and EFF).

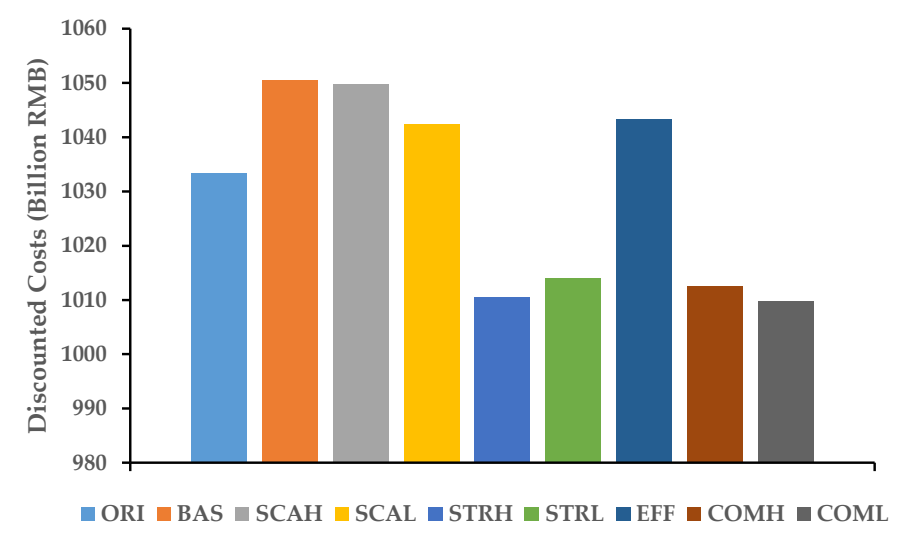

Figure 8. Total discounted costs under different scenarios. 


\subsubsection{Comparisons of External Purchased Electricity under Different Scenarios}

Figure 9 shows the amount of electricity that needs to be purchased from the external grid during the planning horizon to achieve a balance of electricity supply and demand and the safety of the region. With the rapid development of the regional economy, the demand for electricity continues to increase. Of these nine scenarios, the SCAH scenario has the highest demand for electricity, with an average annual growth rate of $6.65 \%$, since the key assumption of the highest GDP growth rate of $7.5 \%$ was considered in this scenario. As for the STRH, STRL, and COML scenarios that are mentioned above, the COML scenario stands out from the three scenarios because of the least amount of electricity purchased. Furthermore, there is little difference in the amount of external purchased electricity between ORI and COML scenarios. However, the ORI scenario is not as good as the COML scenario in terms of total discounted costs. Based on the above analysis, it can be concluded that the development mode of the COML scenario will become the optimal development path for future power generation expansion planning.

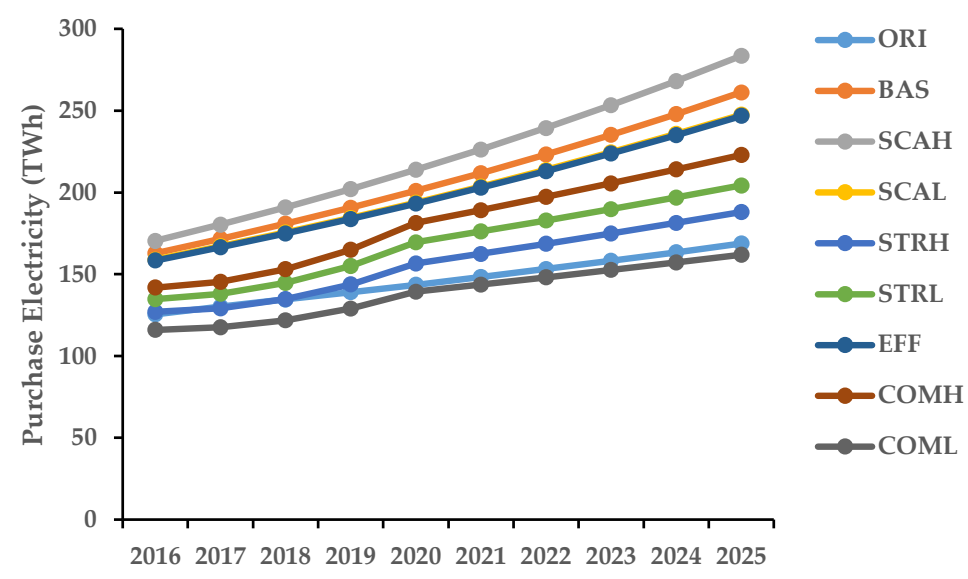

Figure 9. External purchased electricity under different scenarios.

\section{Conclusions}

An attempt has been made to research provincial power generation expansion problem from the perspective of electricity demand uncertainty. A corresponding model has been established and successfully applied to the case study of Zhejiang Province's power planning for the horizon from 2016 to 2025 with consideration of biomass and nuclear power plants. The objective function of this model is to minimize the total discounted cost of the entire system, including investment cost, O\&M cost, fuel cost, environment cost, and electricity procurement cost, through which some meaningful conclusions have been obtained and summarized as follows:

(1) Although the total installed capacity of nuclear power plants accounts for only $9.56 \%$ of the total installed capacity during the planning horizon, their power generation capacity is ranked after the coal-fired plants, owing to the high capacity factor, and has become another major source of maintaining the balance of supply and demand in Zhejiang's power system. When compared with other power generation technologies, the installed capacity proportion of biomass power plants is not large and it provides only $37.18 \mathrm{TW}-\mathrm{h}$ (1.31\% of the total power generation) during the planning horizon. However, their role in reducing environmental pollution is indispensable. In spite of the fastest growth rate of installed capacity for renewable energy technologies (wind and solar PV plants), coal-fired plants and natural gas plants still dominate in total installed capacities.

(2) The lowest total discounted cost is 1033.28 billion RMB during the planning horizon. However, given the fact that the power generation structure of Zhejiang Province is dominated by fossil 
fuel power plants, the fuel cost accounts for a large part of the total cost (about 69\%). In the near future, the investment proportions of renewable energy power plants and nuclear power plants should be increased from the perspective of economic costs and environmental protection, since they can become a good substitute for fossil fuel power plants and reduce fuel cost to some extent. Besides, the external electricity procurement cost also accounts for a large part (about $16.36 \%$ ). Moreover, the environmental cost for the system can be largely reduced by taking effective measures into account, including improving the proportion of renewable energy power plants.

(3) Electricity demand is closely related to many factors, and electricity demand values under various scenarios are different since they have different key performance indicators. The SCAH scenario always has the highest electricity demand values during the planning horizon, which indicates that the GDP growth rate will become the primary KPI affecting the electricity demand. However, other factors cannot be overlooked. In the process of power planning, only the comprehensive consideration of various factors will enable policy-makers to obtain the most reliable results.

(4) The optimization results of the ORI and COML scenarios are very similar, whether it is the electricity demand, the proportion of external purchased electricity, the proportions of various costs, or the values of some key techno-economic data, which verifies that the results derived from ORI scenario are true and authentic. Nevertheless, in view of the total discounted cost, the ORI scenario is not as superior as COML scenario, and the development mode of COML scenario should be adopted by policy-makers to obtain the optimal future power development path.

Author Contributions: P.W. designed the research, established the model, completed the data arrangement and calculation, created the tables and figures, and finished the writing of this paper. C.W., L.V. and W.W. reviewed the paper and provided valuable opinions during the manuscript writing. Y.H. helped with the structuring, writing the paper and analyzing the results. All authors read and approved the final manuscript for submission.

Acknowledgments: This research is supported by the National Natural Science Foundation of China (61573381) and the Engineering and Physical Sciences Research Council (EPSRC, EP/P004636/1, UK).

Conflicts of Interest: The authors declare no conflict of interest.

\section{References}

1. Zeng, L.; Zhao, L.; Wang, Q.; Wang, B.; Xie, Y.; Ma, Y.; Cui, W. Modeling interprovincial cooperative energy saving in China: An electricity utilization perspective. Energies 2018, 11, 241. [CrossRef]

2. Wang, B. Energy Poverty in China: A Dynamic Analysis Based on a Hybrid Panel Data Decision Model. Energies 2017, 10, 1942. [CrossRef]

3. Zhang, J.; Hu, Z.; Zheng, Y.; Zhou, Y.; Wan, Z. Sectoral Electricity Consumption and Economic Growth: The Time Difference Case of China, 2006-2015. Energies 2017, 10, 249. [CrossRef]

4. Chen, H.; Tang, B.J.; Liao, H.; Wei, Y.M. A multi-period power generation planning model incorporating the non-carbon external costs: A case study of China. Appl. Energy 2016, 183, 1333-1345. [CrossRef]

5. Luz, T.; Moura, P.; de Almeida, A. Multi-objective power generation expansion planning with high penetration of renewables. Renew. Sustain. Energy Rev. 2018, 81, 2637-2643. [CrossRef]

6. Chen, Q.; Kang, C.; Xia, Q.; Zhong, J. Power generation expansion planning model towards low-carbon economy and its application in China. Power Syst. IEEE Trans. 2010, 25, 1117-1125. [CrossRef]

7. Jin, S.W.; Li, Y.P.; Huang, G.H.; Zhang, K. Inexact mixed-integer programming with interval-valued membership function for sustainable power-generation capacity planning. J. Clean. Prod. 2016, 122, 52-66. [CrossRef]

8. Cheng, R.; Xu, Z.; Liu, P.; Wang, Z.; Li, Z.; Jones, I. A multi-region optimization planning model for China's power sector. Appl. Energy 2015, 137, 413-426. [CrossRef]

9. Rentizelas, A.; Georgakellos, D. Incorporating life cycle external cost in optimization of the electricity generation mix. Energy Policy 2014, 65, 134-149. [CrossRef] 
10. Zhang, X.; Yan, P.; Zhong, J.; Guo, X.; Tian, C. Generation expansion planning model incorporating environment cost and demand side management programs. Dianwang Jishu/Power Syst. Technol. 2015, 39, 2809-2814. [CrossRef]

11. Feng, Y.; Ryan, S.M. Scenario construction and reduction applied to stochastic power generation expansion planning. Comput. Oper. Res. 2013, 40, 9-23. [CrossRef]

12. Perwez, U.; Sohail, A.; Hassan, S.F.; Zia, U. The long-term forecast of Pakistan's electricity supply and demand: An application of long range energy alternatives planning. Energy 2015, 93, 2423-2435. [CrossRef]

13. McPherson, M.; Karney, B. Long-term scenario alternatives and their implications: LEAP model application of Panama's electricity sector. Energy Policy 2014, 68, 146-157. [CrossRef]

14. Tang, B.J.; Li, R.; Li, X.Y.; Chen, H. An optimal production planning model of coal-fired power industry in China: Considering the process of closing down inefficient plants and developing CCS technologies. Appl. Energy 2017, 206, 519-530. [CrossRef]

15. The Electric Power Development Planning of Zhejiang Province "in 13th Five-Year" (2016-2020). Available online: http://www.chinasmartgrid.com.cn/news/20160923/619192.shtml (accessed on 23 September 2016).

16. Projected Costs of Generating Electricity of 2015 Edition from International Energy Agency. Available online: http:/ / www.iea.org/publications/freepublications/publication/ElecCost2015.pdf (accessed on 30 September 2015).

17. Zhang, M.; Zhou, D.; Ding, H.; Jin, J. Biomass Power Generation Investment in China: A Real Options Evaluation. Sustainability 2016, 8, 563. [CrossRef]

18. Model for Comparing and Projecting the Levelised Cost of Electricity Generated by New Gas, Coal, Nuclear Power Stations and Wind Energy (On- and Offshore). Available online: http://proceedings.ewea.org/ annual2013/allfiles2/1366_EWEA2013presentation.pdf (accessed on 20 November 2013).

19. Wang, P.; Wang, C.; Hu, Y.; Liu, Z. Analysis of energy consumption in Hunan Province (China) using a LMDI method based LEAP model. Energy Procedia 2017, 142, 3160-3169. [CrossRef]

20. Notice on the Related Items of Electricity Price Adjustment from Price Bureau of Zhejiang Province. Available online: http:/ /jf.zjpi.gov.cn/Index/JFFileData (accessed on 8 January 2016).

21. The Cost of External Electricity Purchase Is Greatly Reduced. Available online: http://www.sohu.com/a/ 166147667_771462 (accessed on 21 August 2017).

22. Energy Conservation and Environmental Protection Situation of Power Generation Enterprises of Zhejiang Province in 2016. Available online: http:/ / www.cpnn.com.cn/jnhb/hyzx/201712/t20171215_1040152.html (accessed on 15 December 2016).

23. Heaps, C.G. Long-Range Energy Alternatives Planning (LEAP) System; Stockholm Environment Institute: Somerville, MA, USA, 2016; Software version: 2018.1.4; Available online: https:/ / www.energycommunity. org (accessed on 4 January 2018).

24. Social Development Planning of Zhejiang Province "in 13th Five-Year" (2016-2020). Available online: http:/ / www.zjdpc.gov.cn/art/2016/11/21/art_8_1718219.html (accessed on 21 November 2016).

25. National Economic and Social Development of Zhejiang Province "in 13th Five-Year" (2016-2020). Available online: http:/ / zj.people.com.cn/n2/2016/0201/c186806-27665929.html (accessed on 1 February 2016).

(C) 2018 by the authors. Licensee MDPI, Basel, Switzerland. This article is an open access article distributed under the terms and conditions of the Creative Commons Attribution (CC BY) license (http://creativecommons.org/licenses/by/4.0/). 